\title{
Numerical Simulation on Damage Mode Evolution in Composite Laminate
}

\author{
Jean-Luc Rebière \\ Laboratoire d'Acoustique de l'Université du Maine (UMR CNRS 6613) \\ Université du Maine \\ Av. Olivier Messiaen, 72085 Le Mans Cedex 9, France
}

\begin{abstract}
The present work follows numerous numerical simulation on the stress field analysis in a cracked cross-ply laminate. These results lead us to elaborate an energy criterion. This criterion is based on the computation of the partial strain energy release rate associated with all the three damage types: transverse cracking, longitudinal cracking and delamination. The related criterion, linear fracture based approach, is used to predict and describe the initiation of the different damage mechanisms. With this approach the influence of the nature of the material constituent on the damage mechanism is computed. We also give an assessment of the strain energy release rates associated with each damage mode. This criterion checked on glass-epoxy and graphite-epoxy composite materials will now be used in future research on new bio-based composite in the laboratory.
\end{abstract}

Keywords-numerical simulation; damage mechanism; transverse cracking;longitudinal cracking; delamination; criterion

\section{INTRODUCTION}

During the last years, composite laminates are widely used in many structural applications thanks to their high strength to weight ratio. Their durability still needs to be carefully assessed. So, it is desirable to be able to rely on a suitable damage-growth criterion. Most of these type of composite laminates are composed with glass or graphite long fibers and polymer matrix. Experimentally, in this composite cross-ply laminate subjected to monotonic or fatigue tensile loading, the damage mechanisms sequence is as follows. The first observed damage is generally transverse cracking, causes by interlaminar stress concentration at the crack tips. High interlaminar stress levels may entail the debonding of layers at the interface of the plies with different orientations and/or they may also cause matrix cracking between fibres in the longitudinal layers. The composite structures damaged by incipient delamination or longitudinal cracking must be repaired. The main objective of this work is to evaluate the influence of the nature of the material system on the initiation and evolution of transverse crack damage, longitudinal crack damage and delamination.

For the study of transverse cracking damage, two particulars states are generally observed: the initiation of the first damage called "first ply failure $(F P F)$ " and the limiting state of this damage, named "characteristic damage state $(C D S)^{\prime \prime}$, when no more transverse crack can be created. The second type of damage observed is either longitudinal cracking or delamination. This second type of damage generally depends on following parameters: the laminate geometry, thicknesses of the $0^{\circ}$ or $90^{\circ}$ layers, the nature of the fibre (graphite, glass...)/matrix constituents, the loading history and the manufacturing cycle. For example, in [1] the initiation and growth of delamination was observed in a thick composite laminate. Ply separation is provoked by the increase of interlanimar normal and shearing stresses. In case of thin composite laminates, the damage mode succession can be different. In $[1,2]$ the second damage observed is longitudinal cracking which follows transverse cracking. In this case, local delamination appears between $0^{\circ}$ and $90^{\circ}$ layers. In every case, all the different damage modes causes fibre breaking in the $0^{\circ}$ layers. All fibre breaks entail, named "splitting", which appears just before the ultimate failure of the composite laminate.

In the literature, analytical and numerical approaches have been proposed for modelling the strain/stress relationship during damage growth mechanism. Some models are more suitable to describe the initiation of the first damage mode. They mainly rely on some stress field distribution and a relationship between loading and crack density is usually proposed. The simplest models like Steif [3], so called "shear lag analyses", usually involve elementary assumptions using the displacement and stress distributions. Other type of models like variational approaches [4] use the principle of minimum complementary energy [5-7]. Other types of studies use the finite element method [8]. We can also find some models based on phenomenological approaches [9], self-consistent analyses [10] or approaches based on specific aspects of the cracks [1114]. The longitudinal cracking is equivalent to transverse cracking damage, but arise in the longitudinal plies $\left(0^{\circ}\right.$ layers). Longitudinal cracks are not always continuous [15]. Generally longitudinal cracking occur very late in the laminate life. So, the investigation of longitudinal cracking is often ignored by many models in the literature. Relying on experimental observations, with this approach we suppose that the longitudinal cracks are continuous and that they span the whole length of the damage studied specimen. For the study of delaminated damage, a delaminated surface with a triangular shape at the crossing of longitudinal and transverse cracks was used for estimate the initiation of the interface debonding between orthogonal plies. In this article, we also study the initiation of delaminated surface with triangular shape.

In the literature, several approaches have been proposed to investigate the evolution of the different types of damage in composite cross-ply laminates and several kinds of criteria have been proposed [16], among them maximum stress based 
approaches. We can also find other types of criteria [15] rely on the energy release rates associated with each type of damage.

Our interest in damage mechanism evolution and succession lead us to bring out the respective contributions of the transverse crack damage, longitudinal crack damage or delamination damage mechanism development which can be found in the strain energy release rate for the two materials constituents. The strain energy release rate is expressed through an appropriate semi-analytical model [15] and decomposed into individual components related to damage mechanisms. Opposing to the simplest models of the literature, which only take into account only the normal stress in the loading direction, the general proposed model used here allows a thorough investigation of the strain energy release rate to be achieved. The present study is only restricted to damage growth in cross ply laminates. After numerous numerical simulations, it could be established that the influence of a given component of the stress field on some of the damage mechanisms can be neglected (some shear components). Concerning the initiation of transverse cracking, this kind of assumption gives good results. However, when the evolutions of transverse cracking or the transition to other types of damage are of interest, the simplest damage models cannot be used. In these cases, a more accurate description of the stress field is necessary like the proposed model. In the present article, we further develop the above analysis by first providing the numerical values of the parts of the decomposition of the strain energy release rate associated to each damage type.

\section{MODEL}

The studied specimen is a $\left[0_{m}, 90_{n}\right]_{s}$ composite cross-ply laminate as represented in Fig. 1.

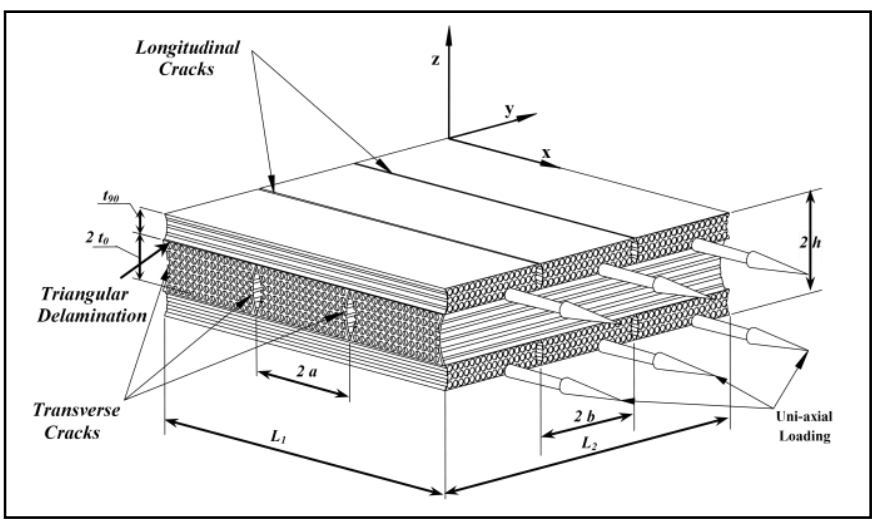

Fig. 1. Laminate damaged by transverse cracks, longitudinal cracks and triangular delamination

The geometric parameters used to describe the laminate architecture is the $\lambda \square$ coefficient $\left(\lambda=t_{0} / t_{90}\right.$ where $t_{0}$ is the $0^{\circ}$ ply thickness and $t_{90}$ is the $90^{\circ}$ ply thickness). With the proposed approach longitudinal cracks are taken continuous by hypothesis [15]. Based on linear elastic fracture mechanics, the estimated values of the strain energy release rates are computed in a "pre-damaged" laminate, a method used in several damage models in the literature. Thus, there are already "pre- existing" transverse and longitudinal cracks and/or triangular delamination at the crack type.

Then, the evolution of transverse cracking damage is described in the following way. We consider a laminate with a periodic array of transverse cracks in the inner $90^{\circ}$ layer. Damage initiation of matrix cracking occurs when the spacing between two consecutive cracks is very important (infinite). For studying longitudinal cracking a similar method can be used. The laminate is supposed to be "pre-cracked". The initiation of the longitudinal damage is obtained for an infinite value of the damage parameter (ratio of the spacing between two consecutive cracks to the central damaged layer thickness).

The accepted assumptions for the crack geometries in the $0^{\circ}$ and $90^{\circ}$ layers of the laminate are as follows. The cracks surfaces are supposed to have a rectangular plane geometry. Each crack extends over the whole thickness and the whole width of the $90^{\circ}$ damaged ply. Similar assumptions are used for the longitudinal cracks in the two damaged $0^{\circ}$ layers. With these assumptions, it is sufficient to study the only "unit damaged cell". This "unit damaged cell"' thus lies between two consecutive transverse and longitudinal cracks. Triangular delaminated areas are located at the cross of transverse and longitudinal cracks at the interface of the $0 \% 190^{\circ}$ plies. For the initiation of delamination the size in the $x$ direction $\left(d_{x}\right)$ and in the $y$ direction $\left(d_{y}\right)$ is supposed to be equal and called $d_{l}$. In [15] the summary of the method is exposed to estimate the stress field distribution in the cracked laminate. In the damaged laminate, the stress field in the two layers has the following form:

$$
\sigma_{i j}^{T(k)}=\sigma_{i j}^{0(k)}+\sigma_{i j}^{P(k)}
$$

In the undamaged laminate loaded in the $x$ direction, the layers experience a uniform plane stress state $\sigma_{i j}^{0(k)}$ obtained by the laminate plate theory (where $k$ is the ply index, $k=0^{\circ}, 90^{\circ}$ ). The orthogonal cracks induce stress perturbations in the $0^{\circ}$ and $90^{\circ}$ layers which are denoted $\sigma_{i j}^{T(k)}$ [15].

\section{StRAIN ENERGY RELEASE RATE}

The laminate is supposed to be "pre-damaged" by "preexisting" transverse and longitudinal cracks. The size of the unit damaged cell depends on the transverse and longitudinal damage levels in the $90^{\circ}$ and $0^{\circ}$ layers. The strain energy release rate $G$ associated with the initiation and development of ply cracking for a given stress state is defined by the following expression:

$$
G=\frac{d}{d A} \widetilde{U}_{d}(\sigma, A)
$$

With:

$$
\widetilde{U}_{d}=N \cdot M \cdot U_{c e l}
$$

where $\widetilde{U}_{d}$ is the strain energy of the whole laminate and $A$ is the cracked area. Let $L_{1}$ denote the laminate length in the $x$ direction and $L_{2}$ its width in the $y$ direction. The strain energy in the damaged unit cell is denoted by $U_{c e l} . N\left(N=L_{1} / 2 \bar{a} t_{90}\right)$ is the number of transverse cracks and $M\left(M=L_{2} / 2 \bar{b} t_{90}\right)$ is the number of longitudinal cracks. Dimensionless quantities are defined by, $\bar{a}=a / t_{90}, \bar{b}=b / t_{90}$. 
The crack area is $A=L_{1} L_{2}(1 / \bar{a}+\lambda / \bar{b})$. The strain energy release rates associated with transverse and longitudinal cracking are denoted $G_{F T}$ and $G_{F L}$ respectively. The transverse (resp. longitudinal) cracking growth is characterized by the increase of the transverse (resp. longitudinal) crack surface initiated in the $90^{\circ}\left(\right.$ resp. $\left.0^{\circ}\right)$ layers. All details are given in [15]. Then:

$$
\begin{aligned}
& G_{F T}=\frac{d \widetilde{U}_{d}}{d A}=\frac{d \widetilde{U}_{d}}{d \bar{a}} \frac{d \bar{a}}{d A} \\
& G_{F L}=\frac{d \widetilde{U}_{d}}{d A}=\frac{d \widetilde{U}_{d}}{d \bar{b}} \frac{d \bar{b}}{d A}
\end{aligned}
$$

The strain energy release rates associated with delamination is $G_{d e l}$, we get :

$$
G_{d e l}=\frac{d \widetilde{U}_{d}}{d \overline{d_{l}}} \frac{d \overline{d_{l}}}{d A_{d}}
$$

For the analysis of the delamination evolution, only isosceles triangular geometries of the debonded area are studied. In [1], the authors have experimentally observed similar triangular areas for the initiation of delamination whereas during its propagation, damage can grow along the longitudinal and/or transverse cracks.

\section{RESULTS}

All the numerical simulations are carried out for a prescribed uni-axial loading of $150 M P a$. The glass/epoxy and T300-934 graphite/epoxy material system are studied in the following numerical computations of the strain energy release rate.

The energetical criterion proposed is elastic linear fracture based approach. The parameters involved in the study are the constraining parameter, the thickness of the two $0^{\circ}$ and $90^{\circ}$ layers and the material constituent system. All the partial strain energy release rates, associated with the initiation of transverse cracking, longitudinal cracking or delamination are normalized by the critical strain energy release rate. For this 8 ply cross-ply laminate, transverse cracking is thus the first observed damage. We can also observe that the strain energy release rates, $G_{F T} / G_{c r}, G_{F L} / G_{c r}$ and $G_{d e l} / G_{c r}$ have similar variation laws for all the computed materials.

In Fig. 2-4 the results of only two types of materials are exposed. We can observe with all the $G_{F T} / G_{c r}, G_{F L} / G_{c r}$ and $G_{d e l} / G_{c r}$ values that in graphite/epoxy laminate, it is more difficult to initiate the three damage modes than in the glass/epoxy laminate. All the strain energy release rates are decreasing functions of the constraining parameter $\lambda$. For instance, in a 8 ply laminate, when the value of the constraining parameter $\lambda$ is increased, the thickness of the $0^{\circ}$ plies becomes greater. In this case, the fibers in the $0^{\circ}$ plies carry most of the tensile loading and the initiation of the three different damage modes is delayed. Although no experimental data are reported on Fig. 2-4, the results of the numerical simulations confirm the main points: the proposed approach agrees with experimental data for the influence of the material constituent and the initiation of transverse cracking is the first damage mode. It also predicts the readiness to initiate the three types of damage in the case of a 8 ply laminate containing a thick $90^{\circ}$ layer. Experimentally, it was observed that, after a certain loading level, the number of longitudinal cracks can become more and more important [1]. At this loading level, delamination can appear along the longitudinal cracks; moreover, some small induced transverse cracks can appear along the longitudinal cracks with delaminated areas.

TABLE I. MECHANICAL PROPERITES AND PLY THICKNESS FOR GLASS EPOXY AND T300/934 GRAPHITE EPOXY SYSTEMS

\begin{tabular}{|c|c|c|}
\hline & Glass/Epoxy & T300/934 Graphite / Epoxy \\
\hline$E_{L T}(G P a)$ & 41.7 & 144.8 \\
\hline$E_{T T}(G P a)$ & 13 & 11.7 \\
\hline$G_{L T}(G P a)$ & 3.4 & 6.5 \\
\hline$G_{T T}(G P a)$ & 4.58 & 3.5 \\
\hline$v_{L T}$ & 0.3 & 0.3 \\
\hline$v_{T T}$ & 0.42 & 0.54 \\
\hline $\begin{array}{c}\text { Ply thickness } \\
(\text { mm })\end{array}$ & 0.203 & 0.132 \\
\hline
\end{tabular}

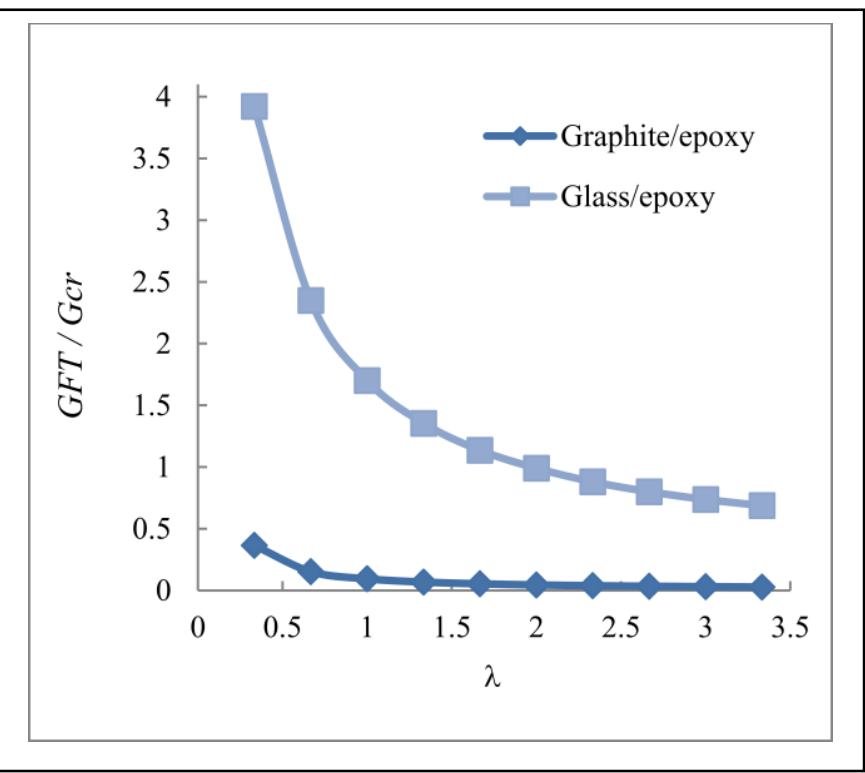

Fig. 2. Strain energy release rate $G_{F T} / G_{c r}$ in laminate $T 300 / 934$ graphite epoxy and glass epoxy versus constraining parameter $\lambda$. 


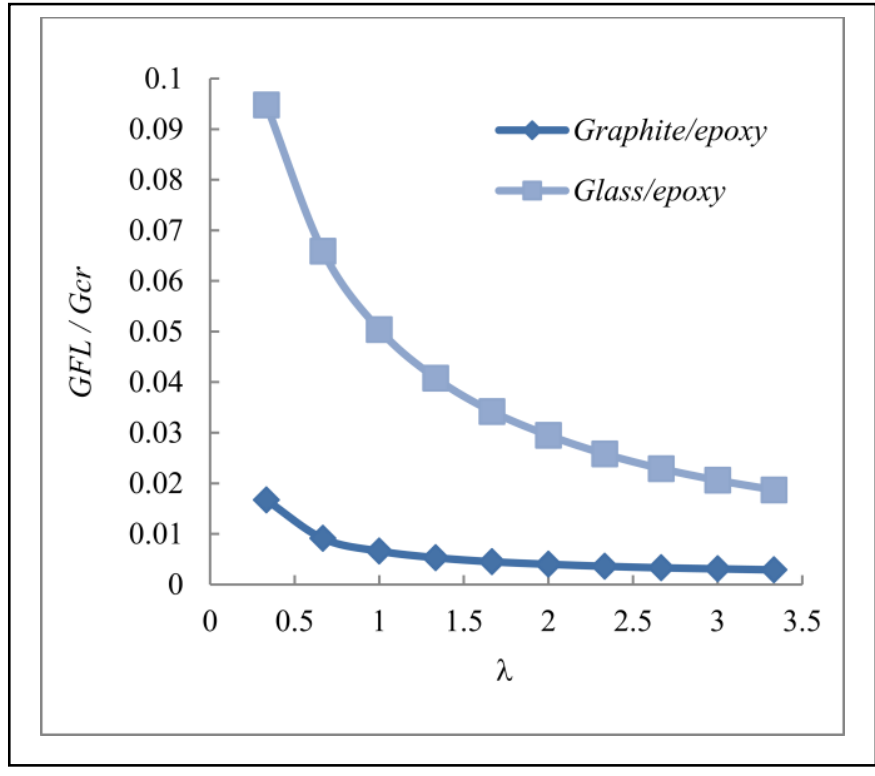

Fig. 3. Strain energy release rate $G_{F L} / G_{c r}$ in laminate $T 300 / 934$ graphite epoxy and glass epoxy versus constraining parameter $\lambda$.

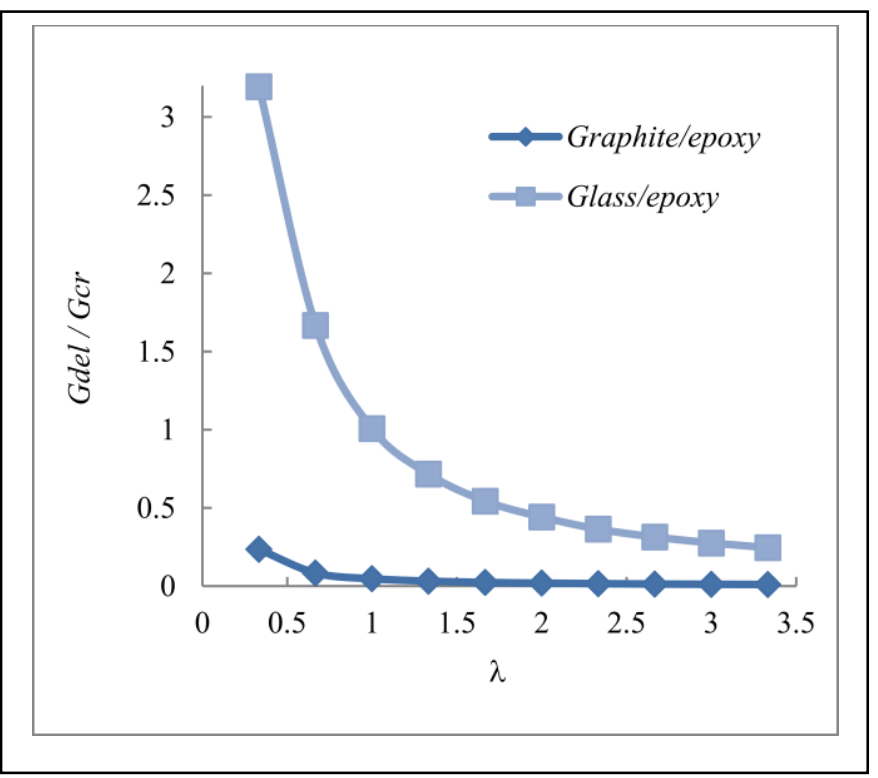

Fig. 4. Strain energy release rate $G_{d e l} / G_{c r}$ in laminate $T 300 / 934$ graphite epoxy and glass epoxy versus constraining parameter $\lambda$.

\section{CONCLUSION}

The energetical criterion is proposed to predict and describe the initiation of the different damage mechanisms occurring in symmetrical composite cross-ply laminates under uniaxial loading. The influence of the material constituent is exposed. All the numerical simulation that the variation of the strain energy release rates as function of the constraining parameter $\lambda$ is similar for the two types of material constituent system. The difference lies in the numerical values of the strain energy release rates. This result shows that it is more difficult to initiate damage in graphite/epoxy laminate. The strain energy release rates are always computed in a "pre damaged" state, with "pre-existing" transverse and longitudinal cracks. The curves displayed confirm that transverse cracking first occurs in the $90^{\circ}$ layers and longitudinal cracking arrive at the end of the laminate life for important value of the crack density. In a 8 ply laminate, when the value of the constraining parameter is increased, the thickness of the $0^{\circ}$ plies becomes greater and carry most of the loading and the initiation of the three damage is delayed.

\section{REFERENCES}

[1] E. Urwald, "Influence de la géométrie et de la stratification sur l'endommagement par fatigue de plaques composites carbone/époxyde"', Ph.D. dissertation. Université de Poitiers; 1992.

[2] R.-D. Jamison, K. Schulte, K.-L. Reifsnider, W.-W. Stinchcomb, "Characterization and analysis of damage mechanisms in tensiontension fatigue of Graphite/Epoxy laminates. Effects of Defects in Composites Materials", ASTM STP 836, American Society for Testing and Materials, 1984, pp. 21-55.

[3] P.S. Steif "Parabolic shear-lag analyses of a $[0 / 90]_{\mathrm{s}}$ laminate. In: Transverse crack growth and associated stiffness reduction during the fatigue of a simple crossply laminate", eds.: Ogin S.L., Smith P.A., Beaumont P.W.R. Report CUED/C/MATS/TR 105, Cambridge University, 1984, pp. 40-41.

[4] J. Lemaître, J.-L. Chaboche, "Mechanics of Solid Materials", Cambridge University Press, 1994.

[5] V.V. Vasil'ev, A.A. Duchenco, "Analysis of the tensile deformation of glass-reinforced plastics", Translated from Mekhanica Polimerov.; vol 1, 1970, pp.144-147.

[6] A. Hosoi, H. Kawada, "Stress analysis of carbon fiber reinforced plastics, containing transverse cracks, considering free-edge effect and residual thermal stress", Mater Sci Eng A, vol. 4498, No 1-2, 2008, pp. 69-75. Doi:10.1016/j.msea.2007.11.153

[7] J.-L. Rebière,'Modélisation du champ des contraintes créé par des fissures de fatigue dans un composite stratifié carbone/polymère', Ph.D. dissertation, Université de Poitiers, 1992.

[8] C.T. Herakovich, J. Aboudi, S. W. Lee, E. A. Strauss, 'Damage in composite laminates: effects of transverse cracks", Mech Mater., vol. 7, No 2, 1988, pp. 91-107.

[9] G. Lubineau, P. Ladevèze, D. Violeau, "Durability of cfrp laminates under thermomechanical loading: a micro-meso damage model", Compos Sci Technol, vol. 66, No 7-8, 2006, pp. 983-92.

[10] S. Adali, R. K. Markins, "'Effect of transverse matrix cracks on the frequencies of unsymmetrical, cross-ply laminates", J the Franklin Institute.; vol. 329, No 4, 1992, pp. 655-665.

[11] Barbero E. J., Cortes D. H., " A Mechanistic Model for Transverse Damage Initiation, Evolution, and Stiffness Reduction in Laminated Composites. "Composites Part B; vol. 41/2, 2010, pp.124-132.

[12] Yokozeki T., Aoki T., Ishikawa T., "Consecutive matrix cracking in contiguous plies of composite laminates", Inter J Solids and Struct.; vol. 42, 2005, pp.2785-2802.

[13] M.M. Moure, S. Sanchez-Saez, E. Barbero, E.J. Barbero, ”Analysis of damage localization in composite laminates using a discrete damage mode', Composites Part B: Engineering, In Press, Accepted Manuscript, Available online 23 May 2014.

[14] G. Sadeghi, H. Hosseini-Toudeshky, B. Mohammadi, "An investigation of matrix cracking damage evolution in composite laminates Development of an advanced numerical tool', Compos Struct, vol. 108, 2014, pp. 937-950.

[15] J.-L. Rebière, D. Gamby, "A criterion for modelling initiation and propagation of matrix cracking and delamination in cross-ply laminates", Compos Sci Technol, vol. 64, No 13-14, 2004, pp. 22392250. Doi: 10.1016/j.compscitech.2004.03.008

[16] N.-V. Akshantala, R. A. Talreja, "micromechanics based model for predicting fatigue life of composite laminate", Mater Sci Eng A, vol. 285, No 1-2, 2000, pp. 303-313. 